\title{
Solvent transport through carbon black filled poly(ethylene-co-vinyl acetate) composites
}

\author{
K. Priya Dasan ${ }^{1 *}$, G. Unnikrishnan ${ }^{2}$, E. Purushothaman ${ }^{1}$ \\ ${ }^{1}$ Department of Chemistry, University of Calicut, Calicut-673635, India \\ ${ }^{2}$ Polymer science and technology laboratory, NITC, Calicut-673601, India
}

Received 27 January 2008; accepted in revised form 4 April 2008

\begin{abstract}
Poly(ethylene-co-vinyl acetate) (EVA) was reinforced with three different types of carbon black viz. semi-reinforcing furnace (SRF), high abrasion furnace (HAF) and intermediate super abrasion furnace (ISAF). The solvent transport by the composites were analyzed using benzene, toluene and xylene as penetrant molecules. The observed cure characteristics and solvent uptake behaviour of the composites has been explained on the basis of particle size of the filler and bound rubber content. The mode of transport in all the cases was found to be anomalous. A sorption-desorption-resorption (S-D-RS) experiment was carried out to study the physical changes in the polymer matrix, associated with the transport of the solvents through the composites.
\end{abstract}

Keywords: polymer composites, carbon black, EVA, cure characteristics, diffusion coefficient

\section{Introduction}

Molecular transport through polymers has become a subject with a variety of challenges and opportunities for practitioners of chemical engineering and applied chemistry in recent years. The knowledge of the performance of polymers in the environment of hazardous solvents, vapours and temperature is essential for their successful applications as structural engineering materials. The diffusion and permeation properties of polymers play a very major role in designing food packaging materials [1], solvent reservoirs [2], pervaporators [3], controlled release devices $[4,5]$ etc. In order to examine the suitability of a membrane as a barrier material, it is essential to acquire a thorough understanding of its interactions with liquids and vapours.

The influence of carbon black on solvent transport through elastomer networks has gained the attention of scientists for many years. Guth studied the effect of filler reinforcement in elastomers in detail
[6]. Porter [7] studied the degree to which the addition of HAF black reduced the swelling of conventionally vulcanized NR in $n$-decane. De Candia et al. [8] investigated the transport properties of networks filled with carbon black, in order to obtain information about rubber-filler interactions. Kwei and Kumins [9] found that the sorption of chloroform by an epoxy resin was lowered by about $70 \%$ when $5 \%$ filler was added. Anfimova et al. [10] reported the equilibrium swelling in benzene of NR vulcanizates having different degrees of crosslinking, filled with technical carbon. The diffusivity and solubility of argon, methane, oxygen, and carbon dioxide in two EPDM based polymers, one formulated with $34 \mathrm{wt} \%$ carbon black and the other without carbon black, have been studied by Rutherford et al. [11]. A linear relationship was observed between the amount sorbed material and pressure for all gases, indicative of Henry's law behaviour. Choi [12] examined the influence of

*Corresponding author, e-mail: kpriyadasan@yahoo.com

(C) BME-PT and GTE 
temperature on the extraction of bound rubber. For both silica and carbon black filled compounds, the bound rubber content was found to increase with increase in filler-rubber content ratio and decrease with increasing extracting temperature. Activation energy for the extraction of the unbound and loosely bound rubbers became higher as the total filler content increased. Many other reports including those from our laboratory exist regarding carbon black-elastomer interaction and their influence on the mechanical and solvent transport properties of black filled elastomers [13-19].

The main goal of the present chapter is to study the effects of three different types of carbon black fillers viz. semi-reinforcing furnace (SRF), high abrasion furnace (HAF) and intermediate super abrasion furnace (ISAF) on the cure and solvent transport properties of EVA. These properties of the composites were evaluated in terms of particles size and loading of filler.

\section{Experimental}

\subsection{Materials}

EVA used in the present work is obtained from Polyolefin Industries Limited, Chennai, India. The vulcanizing agent used, dicumyl peroxide (40\% active), was of commercial grade. The solvents such as benzene, toluene and xylene were obtained from E. Merck (India) Ltd., Mumbai, India and were of reagent grade (99\%). The properties of the solvents are given in Table 1. The carbon black fillers, SRF (N220), HAF (N330) and ISAF (N770) were of commercial grade. The properties of the fillers are given in Table 2.

\subsection{Mixing}

The mixing of EVA with various ingredients was carried out on a two-roll mixing mill $(150 \mathrm{~mm} \times$ $300 \mathrm{~mm}$ ) with a friction ratio 1:1.4 as per ASTM D15-627. The EVA granules were sheeted out first and then the mixing was carried out. The amount of curing agent, dicumyl peroxide (DCP), was kept constant (4 phr) for all the mixes. Special attention was taken to attain uniform filler distribution. The loading of the fillers are varied as 10,20,30, 40 and $50 \mathrm{phr}$. The formulation of the mixes are given in Table 3.
Table 1. Properties of the solvents

\begin{tabular}{|l|c|c|c|}
\hline \multicolumn{1}{|c|}{ Solvents } & $\begin{array}{c}\text { Molecular } \\
\text { weight }\end{array}$ & $\begin{array}{c}\text { Density } \\
{[\mathbf{g} / \mathbf{c c}]}\end{array}$ & $\begin{array}{c}\text { Boiling point } \\
{\left[{ }^{\circ} \mathbf{C}\right]}\end{array}$ \\
\hline Benzene & 78.11 & 0.874 & 79 \\
\hline Toluene & 92.14 & 0.867 & 109 \\
\hline Xylene & 106.17 & 0.860 & 137 \\
\hline
\end{tabular}

Table 2. Properties of carbon black

\begin{tabular}{|l|c|c|c|}
\hline $\begin{array}{c}\text { Carbon black } \\
\text { type }\end{array}$ & $\begin{array}{c}\text { Particle size } \\
{[\mathbf{n m}]}\end{array}$ & $\begin{array}{c}\text { DBP } \\
\text { absorption } \\
{\left[\mathbf{c m}^{3} / \mathbf{g}\right]}\end{array}$ & $\begin{array}{c}\text { Pour density } \\
{[\mathrm{g} / \mathbf{l}]}\end{array}$ \\
\hline SRF & $61-100$ & 0.70 & 375 \\
\hline HAF & $26-30$ & 1.05 & 375 \\
\hline ISAF & $20-25$ & 1.15 & 345 \\
\hline
\end{tabular}

Table 3. Formulations of EVA/carbon black mixes [phr]

\begin{tabular}{|c|c|c|c|c|}
\hline \multirow{2}{*}{$\begin{array}{c}\text { Sample } \\
\text { code }\end{array}$} & \multicolumn{5}{|c|}{ Ingredients } \\
\cline { 2 - 5 } & EVA & SRF & HAF & ISAF \\
\hline G & 100 & - & - & - \\
\hline S10 & 100 & 10 & - & - \\
\hline S20 & 100 & 20 & - & - \\
\hline S30 & 100 & 30 & - & - \\
\hline S40 & 100 & 40 & - & - \\
\hline S50 & 100 & 50 & - & - \\
\hline H10 & 100 & - & 10 & - \\
\hline H20 & 100 & - & 20 & - \\
\hline H30 & 100 & - & 30 & - \\
\hline H40 & 100 & - & 40 & - \\
\hline H50 & 100 & - & 50 & - \\
\hline I10 & 100 & - & - & 10 \\
\hline I20 & 100 & - & - & 20 \\
\hline I30 & 100 & - & - & 30 \\
\hline I40 & 100 & - & - & 40 \\
\hline I50 & 100 & - & - & 50 \\
\hline
\end{tabular}

\subsection{Cure characteristics and vulcanization}

The cure characteristics were studied by means of an oscillating disc rheometer (Monsanto Rheometer MDR-2000, USA) as per ASTM standard D-5289 (2001). The samples were vulcanized at $160^{\circ} \mathrm{C}$ using a hydraulic press, having electrically heated platens, under a pressure of $689.4 \mathrm{kPa}$ (mould dimension:150 $\times 150 \times 2 \mathrm{~mm}^{3}$ ) to their respective optimum cure time as obtained from the rheographs. Moulds were cooled quickly in water after the curing process. The moulded samples were stored in a cool and dark place for 24 hours.

\subsection{Bound rubber content estimation}

The bound rubber content was estimated according to the procedure suggested by Leblanc and Hardy [20], using benzene as the solvent. About $1 \mathrm{~g}$ of filler loaded non cured EVA sample was cut into 
small pieces and kept immersed in $150 \mathrm{ml}$ benzene for 72 hours at room temperature. The solvent was filtered off, and the remaining sample was dried for a few hours at room temperature and then for 24 hours under vacuum at $40^{\circ} \mathrm{C}$. Complete drying was checked by a constant final weight. Similar methodology has been adopted in many works before [21-24].

The amount of BR (in percentage of initial rubber content of the compound) has been calculated from the Equation (1):

$$
\begin{aligned}
& \mathrm{BR}[\%]= \\
& \qquad \frac{\left(M_{0}-M_{b}\right)-\left[\mathrm{CPD} / 100\left(M_{0}-M_{e}\right)\right]}{\left(M_{0}-M_{b}\right)} \cdot 100
\end{aligned}
$$

where CPD is the total formulation (in phr); $M_{0}$ is the initial weight (bottle + unextracted sample), $M_{b}$ is the empty bottle weight and $M_{e}$ is the final weight (bottle + extracted sample) when dried.

\subsection{Sorption experiments}

The samples for sorption experiments (ASTM D-471) were punched out in circular shape of diameter $1.9 \mathrm{~cm}$ and thickness $0.2 \mathrm{~cm}$ were dried in a vacuum desiccator over anhydrous $\mathrm{CaCl}_{2}$ at room temperature for about $24 \mathrm{~h}$. The original weights and thicknesses of the samples were measured before sorption experiments. They were then immersed in solvents $(15-20 \mathrm{ml})$ taken in closed diffusion bottles, which were kept at constant temperature in an oven. The samples were removed from the bottles at periodic intervals, dried between filter papers to remove the excess solvent on their surfaces and weighed immediately using an electronic balance (Shimadzu, Libror AEU-210, Japan) that measured reproducibly within $\pm 0.0001 \mathrm{~g}$. They were then placed back into the test bottles. The process was continued until equilibrium swelling was achieved. Since the weighing was done within 40 seconds, the error associated with the evaporation of solvents is negligible. Similar methodology has been adopted by several researchers [25-27]. The experiments were duplicated or triplicated in most cases. The results of the sorption experiments have been expressed as moles of solvent sorbed by $0.1 \mathrm{~kg}$ of the sample, $Q_{t}$ mol\%, given by Equation (2). The $Q_{t}$ values obtained thereby have been plotted as a function of square root of time, to construct the sorption curves.

The thickness and diameter of the samples before and after swelling were determined by using gauge micrometer and vernier calipers respectively.

\section{Results and discussion}

\subsection{Cure characteristics}

Figure 1 shows the rheographs of EVA filled with three different types of carbon black at $10 \mathrm{phr}$ filler loading. For all the mixes, the torque increases with time and levels off later. The increase in torque with time is due to the crosslinking of the mixes while the leveling off is an indication of the completion of curing. The maximum torque $\left(M_{H}\right)$ gives an idea about the crosslink density and degree of reinforcement of the filler in the matrix. $M_{H}$ has been found to be higher for the filled samples compared to pure EVA. The increase in $M_{H}$ value is due to the increased restriction to polymer chain mobility and viscosity of the mixes caused by filler reinforcement.

Figure 2 shows the $M_{H}$ values of the mixes at different filler loading. Among the black filled EVA

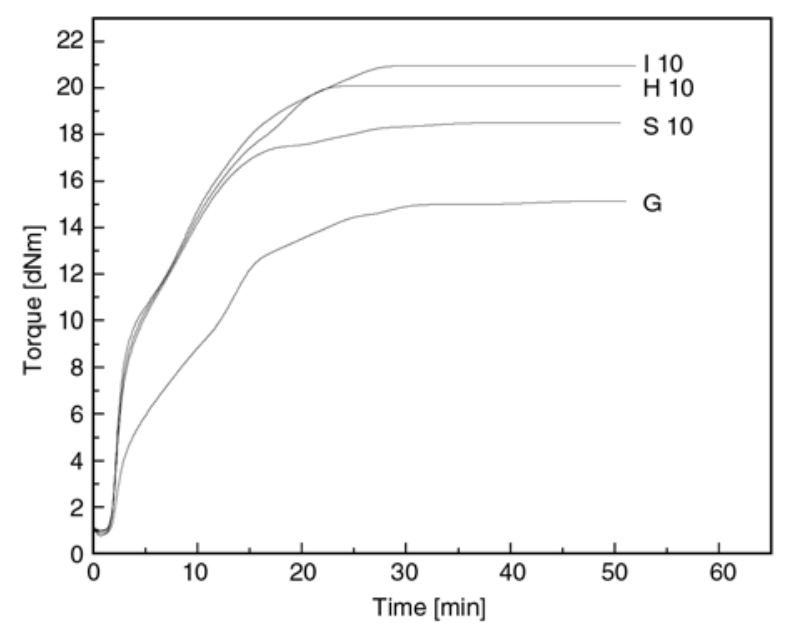

Figure 1. Rheographs of EVA filled with different types of carbon blacks at $10 \mathrm{phr}$ filler loading
$Q_{t}[\%]=\frac{\left[\frac{\text { Weight of solvent sorbed by the sample at a given time }}{\text { Molecular weight of the solvent }}\right]}{\text { Initial weight of the solvent }} \cdot 100$ 


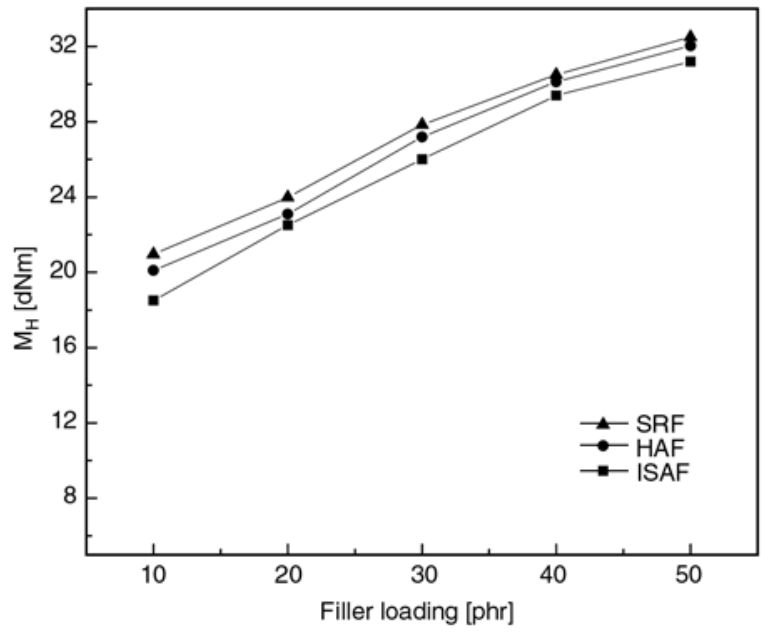

Figure 2. $M_{H}$ values of EVA/carbon black mixes at different filler content

samples, the ISAF filled sample shows the highest $M_{H}$ value followed by HAF and then SRF filled mixes for a given loading. This has been attributed to the difference in particle size of the fillers used. For a given loading of the filler, the effective surface area increases with decreasing particle size. As the surface area of the filler increases, the fillerpolymer interaction increases resulting in higher degree of reinforcement. Therefore ISAF, having the lowest particle size among the fillers used, shows the maximum reinforcement in the matrix and hence the highest $M_{H}$ value. SRF having the highest particle size gives the minimum value of $M_{H}$, while that of HAF filled samples lies in between.

From Figure 2, it is also clear that the torque value increases with increased filler loading. The increment in torque values with increase in filler content indicates that as more and more fillers get reinforced into the matrix, the mobility of macromolecular chains of EVA gets reduced resulting in more rigid vulcanizates.

\subsection{Bound rubber content (BR)}

Bound rubber is the rubber portion that can no longer be separated from the filler when a rubber batch is extracted in a good solvent over a specific period of time, usually at room temperature. It is a measure of the interaction between the polymer and the filler [12]. During the milling process, polymer chain molecules become attached to reinforcing fillers. Therefore they are no longer soluble in usual solvents. This process is the basis for the formation
Table 4. Bound rubber content [\%]

\begin{tabular}{|c|c|}
\hline Type of filler & Bound rubber content [\%] \\
\hline SRF & 42.84 \\
\hline HAF & 45.21 \\
\hline ISAF & 47.26 \\
\hline
\end{tabular}

of bound rubber. It continues after mixing and eventually a system of interconnecting chains and particles results, which appears as an insoluble fragile gel containing filler and part of the bound rubber.

Table 4 shows the bound rubber (BR) content of EVA loaded with different carbon blacks. The bound rubber content has been found to be in the order: ISAF $>$ HAF $>$ SRF filled EVA. Bound rubber results in the formation of gel like structures and enhances the bonding between individual polymeric chains. Therefore polymer chain mobility within the matrix is minimum for ISAF loaded samples and maximum for SRF loaded samples.

\subsection{Sorption properties}

\subsubsection{Effect of filler loading}

Figures 3 and 4 show the sorption curves of unfilled and carbon black filled EVA at $28^{\circ} \mathrm{C}$ in benzene and toluene respectively. It can be seen from the figures that the loading of EVA with carbon black reduces the mol\% solvent uptake. Vulcanization restrains the long-range movements of the polymer molecules but leaves their local segmental mobility high [28]. Reinforcement restricts these local freedoms of movement and thereby improves the sol-

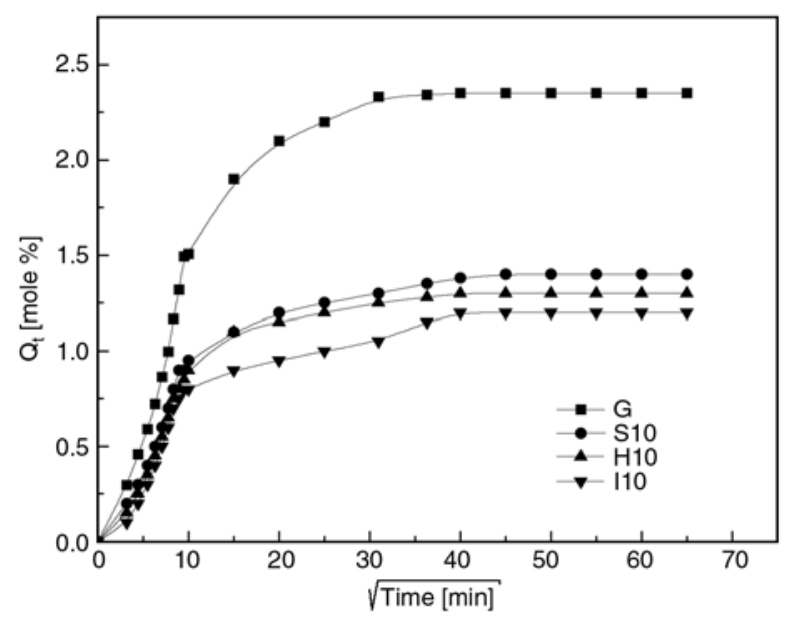

Figure 3. Mol\% benzene uptakes by gum EVA and $\mathrm{EVA} /$ carbon black composites at $10 \mathrm{phr}$ filler loading 


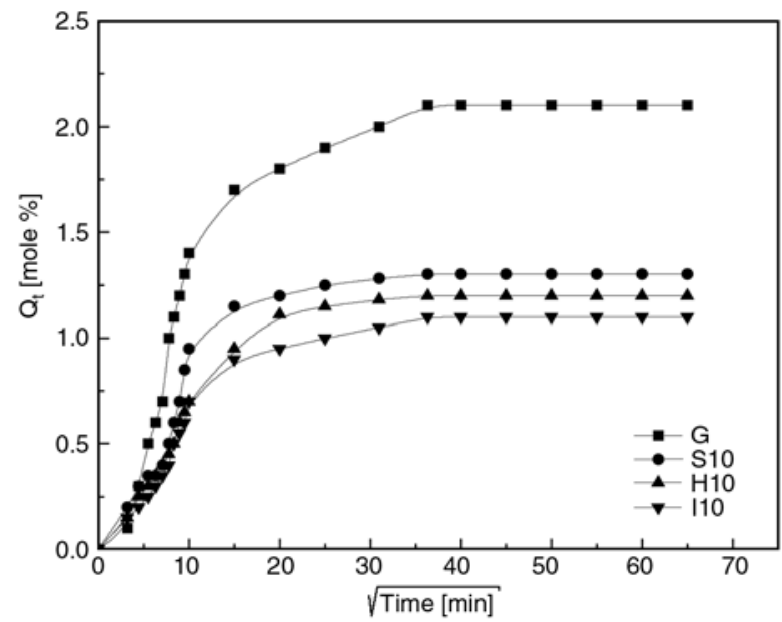

Figure 4. Mol\% toluene uptake by EVA and EVA/carbon black composites at $10 \mathrm{phr}$ filler loading

vent resistance. The fillers form chemical as well as physical crosslinks with the polymer chains, because of which the polymer segments in a certain zone around the filler experiences certain immobilization. This complex crosslink clusters prevent the rearrangement of the polymer chains during solvent ingression and reduces the free volume in the composite, thereby causing resistance to the path of penetrants. Figure 5 gives a schematic representation of the filler reinforced polymer matrix.
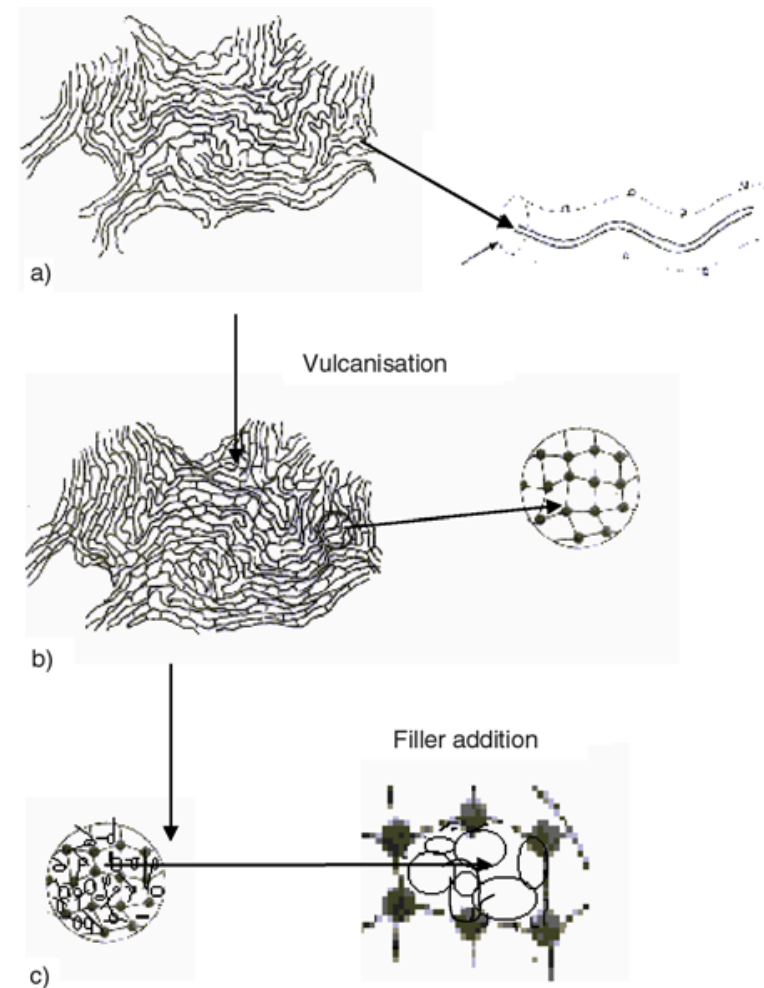

Figure 5. Pictorial representation of (a) unvulcanized polymer, (b) vulcanized polymer, (c) filled polymer
It is also clear from Figures 3 and 4 that EVA loaded with ISAF absorbs the lowest amount of solvents and that with SRF takes up the highest. The samples loaded with HAF take an intermediate position. For a given void, fillers with lower particle size make a more compatible filling than those with higher particle size. The reinforcement of EVA by ISAF black, having the lowest particle size and the highest bound rubber content among the fillers used, causes reduced polymer chain mobility and free volume in the matrix. The SRF black filled composite shows a higher level of solvent uptake because of their high particle size and lower bound rubber content. The reinforcement by HAF lies in between these two. Figure 6 shows a pictorial representation of reinforcement of different types of fillers in EVA matrix. Another reason for the higher reinforcement of ISAF black might be the large number of oxidative groups in their surfaces such as quinone $(>=\mathrm{O})$, phenol $(>-\mathrm{OH})$, carboxylic acid $(>-\mathrm{COOH})$ and lactone $(>-\mathrm{COO}-)$ [29] which result in a higher polarity.

Figure 7 shows the mol\% benzene uptake by SRF filled samples at different filler loadings. Solvent

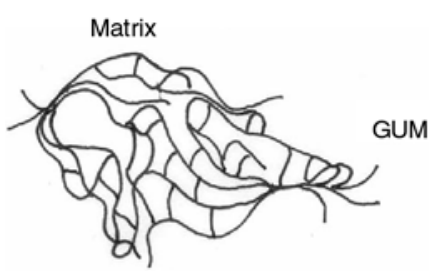

Particle size
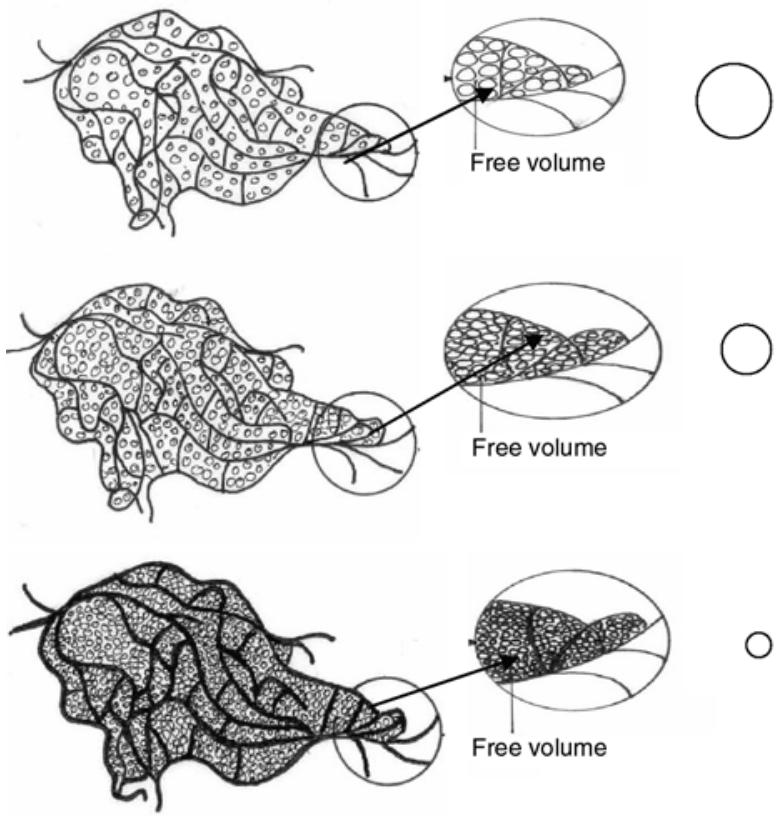

Figure 6. Pictorial representation of reinforcement of EVA with fillers of different particle size 


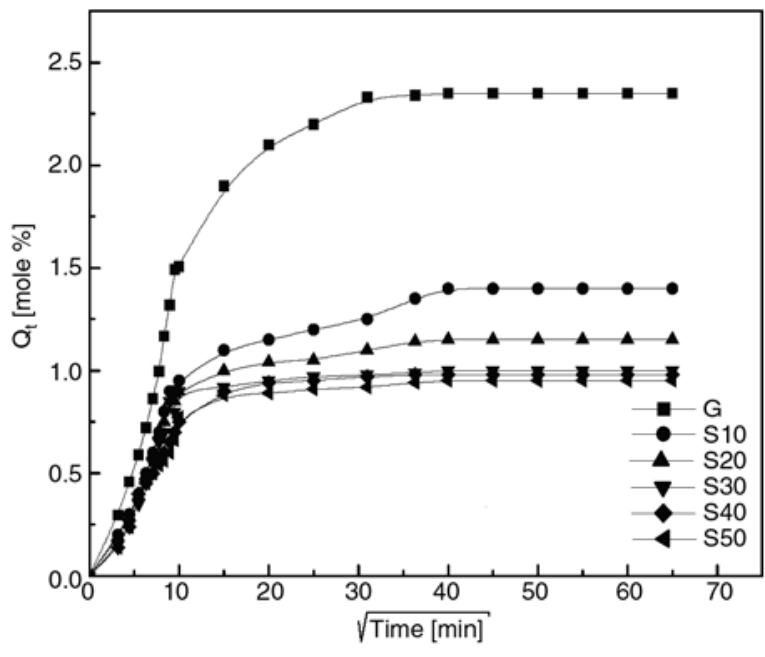

Figure 7. Mol\% benzene uptake by EVA and EVA/SRF composite at different filler loading

uptake has been found to be reduced further with increased filler content. This is due to the decreased free volume and polymer chain mobility in the composite with increased filler concentration.

\subsubsection{Crosslink density}

The crosslink density $(v)$ of the present systems has been estimated by using the Equation (3) [30]:

$v=\frac{1}{2 M_{c}}$

where $M_{c}$ is the molar mass between crosslinks in the composites, given by the Equation (4) [31]:

$$
M_{c}=\frac{-\rho_{p} V_{s} V_{r f}^{1 / 3}}{\left[\ln \left(1-V_{r f}\right)+V_{r f}+\chi V_{r f}^{2}\right]}
$$

where $V_{s}$ is the molar volume of the solvent used, $\rho_{p}$ is the density of the polymer and $\chi$ is the polymer-solvent interaction parameter. $V_{r f}$, the volume fraction of polymer in the solvent swollen filled composite sample, is given by the Equation (5) [32]:

$V_{r f}=\frac{(d-f w) \rho_{p}^{-1}}{(d-f w) \rho_{p}^{-1}+A_{s} \rho_{s}^{-1}}$

where $d$ is the deswollen weight of the sample, $f$ is the volume fraction of filler in the dry composite sample, $w$ the initial weight of the composite sam-

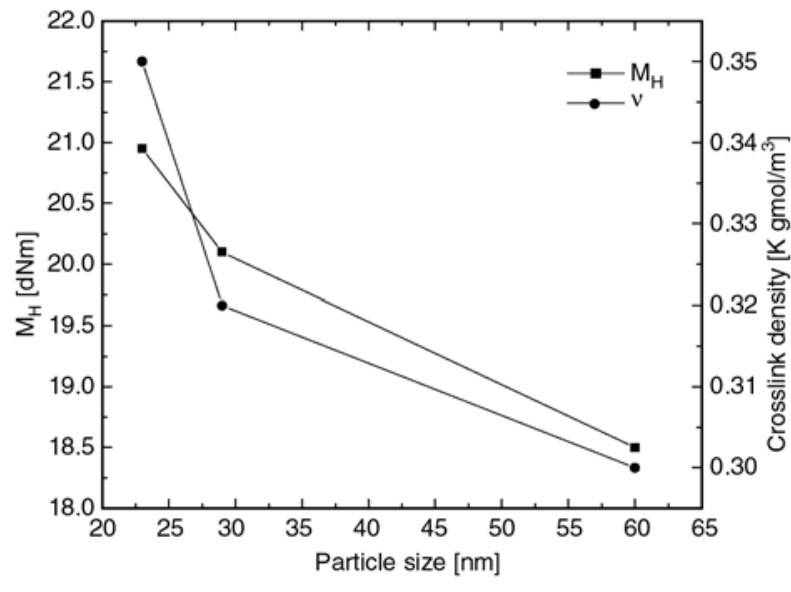

Figure 8. Crosslink density $(v)$ and maximum torque $\left(M_{H}\right)$ of EVA/black composites as a function of particle size of filler

ple, $\rho_{s}$ is the density of the solvent and $A_{s}$, the weight of solvent in the swollen sample.

Figure 8 shows the $v$ and $M_{H}$ of EVA/carbon black composites as a function of the particle size of the filler used. The solvent used was benzene. Both $v$ and $M_{H}$ of the composite have been found to be increasing with decreased particle size of the fillers.

\subsubsection{Diffusion coefficient}

Diffusion coefficient is a kinetic parameter related to the polymer segmental mobility, penetrant nature and to the different crosslinks present in a polymer matrix. The diffusion coefficient of a polymeric material immersed in a solvent can be calculated using the Equation (6) [33]:

$$
\frac{Q_{t}}{Q_{\infty}}=1-\frac{8}{\pi^{2}} \sum_{m=0}^{m=\infty}\left(\frac{1}{(2 m+1)^{2}}\right) e^{-(2 m+1)^{2} \pi^{2} \frac{D \cdot t}{h^{2}}}
$$

where $Q_{t}$ and $Q_{\infty}$ are the mol\% uptake at time $t$ and at equilibrium respectively and $m$ is an integer. $D$ is the diffusion coefficient and $h$ is the initial thickness of the sample. The above Equation (7) can be solved for short time limiting as:

$$
\frac{Q_{t}}{Q_{\infty}}=4\left[\frac{D \cdot t}{\pi h}\right]^{1 / 2}
$$

A plot of $Q_{t}$ versus $\sqrt{t}$ is linear at short times. By rearranging Equation (7), the overall diffusion 
Table 5. Values of diffusion coefficient at $28^{\circ} \mathrm{C}$

\begin{tabular}{|c|c|c|c|}
\hline \multirow{2}{*}{ Sample } & \multicolumn{3}{|c|}{ D·10 $\mathbf{1}^{\mathbf{8}}\left[\mathrm{m}^{2} / \mathbf{s}\right]$} \\
\cline { 2 - 4 } & Benzene & Toluene & Xylene \\
\hline G & 1.50 & 1.40 & 1.28 \\
\hline S10 & 1.12 & 1.01 & 0.95 \\
\hline H10 & 0.94 & 0.88 & 0.81 \\
\hline I10 & 0.93 & 0.83 & 0.75 \\
\hline
\end{tabular}

coefficient can be calculated using the Equation (8) [34]:

$$
D=4\left[\frac{h \cdot \theta_{D}}{4 Q_{\infty}}\right]^{2}
$$

where $\theta_{D}$ is the slope of the initial portion of the plots of $Q_{t}$ versus $\sqrt{t}$. A correction for swelling is made by incorporating $V_{r f}$, thus giving intrinsic diffusion coefficient $D^{*}$ as Equation (9) [35]:

$$
D^{*}=\frac{D}{V_{r f}}
$$

The values of $D^{*}$ at $28^{\circ} \mathrm{C}$ for $10 \mathrm{phr}$ filler loaded EVA composites are given Table 5. It can be seen from the table that for a given solvent, the diffusion coefficient values are in the order: $\mathrm{SRF}>\mathrm{HAF}>$ ISAF filled composites. The diffusion coefficient for gum sample is higher than that of the composites.

\subsubsection{Mode of transport}

The mechanism of transport can be computed from the swelling data using the Equation (10) [36]:

$$
\frac{Q_{t}}{Q_{\infty}}=k \cdot t^{n}
$$

where $k$ indicates the interaction between the penetrant and the polymer and $n$ represents the mode of transport. Taking $\log$ on both the sides, Equation (10) becomes Equation (11): $\log \frac{Q_{t}}{Q_{\infty}}=\log k+n \log t$

The value of $n$ suggests the mode of transport. For the normal Fickian mode of transport, where the rate of polymer chain relaxation is higher compared to the diffusion rate of the penetrant, the value of $n$ is 0.5 . When $n=1$, the transport approaches nonFickian behaviour, where chain relaxation is slower than the liquid diffusion. If the value of $n$ is in between 0.5 and 1 , the mode of transport is classified as anomalous. $k$ is a constant depending on the interaction between the rubber and solvent. The estimated values of $n$ and $k$ for different systems are given in Table 6. It can be seen that the diffusion process in the present case deviates from the regular Fickian trend, observed with conventional rubbers, and can be classified as anomalous. Deviations from the Fickian sorption are associated with the time taken by rubber segments to respond to swelling stress and rearrange themselves to accommodate the solvent molecules. The reinforcement with the filler particle imparts a high degree of restriction to the rearrangement of rubber chains. Thus the observed anomalous diffusion involves the counteraction between the ability of the rubber segments to rearrange in the presence of solvents and the restriction imparted to this by the reinforced filler particles. The $k$ values decrease with increase in the molecular size of the penetrants from benzene to xylene, indicating decreased polymer-solvent interaction.

\subsubsection{Sorption-desorption-resorption (S-D-RS) experiments}

A S-D-RS experiment was carried out to study the physical changes in the matrix with solvent transport [37]. The solvent saturated samples were desorbed completely, and then allowed to sorb the solvent again. The S-D-RS curves of sample S10 in

Table 6. Values of $n$ and $k$

\begin{tabular}{|c|c|c|c|c|c|c|}
\hline \multirow{2}{*}{ Sample } & \multicolumn{3}{|c|}{ n } & \multicolumn{3}{c|}{$\mathbf{k}^{-10^{2}}\left[\mathrm{~min}^{-1}\right]$} \\
\cline { 2 - 6 } & Benzene & Toluene & Xylene & Benzene & Toluene & 2.10 \\
\hline G & 0.64 & 0.68 & 0.69 & 0.14 & 1.90 \\
\hline S10 & 0.71 & 0.74 & 0.75 & 1.21 & 1.98 \\
\hline H10 & 0.72 & 0.75 & 0.77 & 2.11 & 1.99 \\
\hline I10 & 0.74 & 0.76 & & 1.78 & 1.89 \\
\hline
\end{tabular}




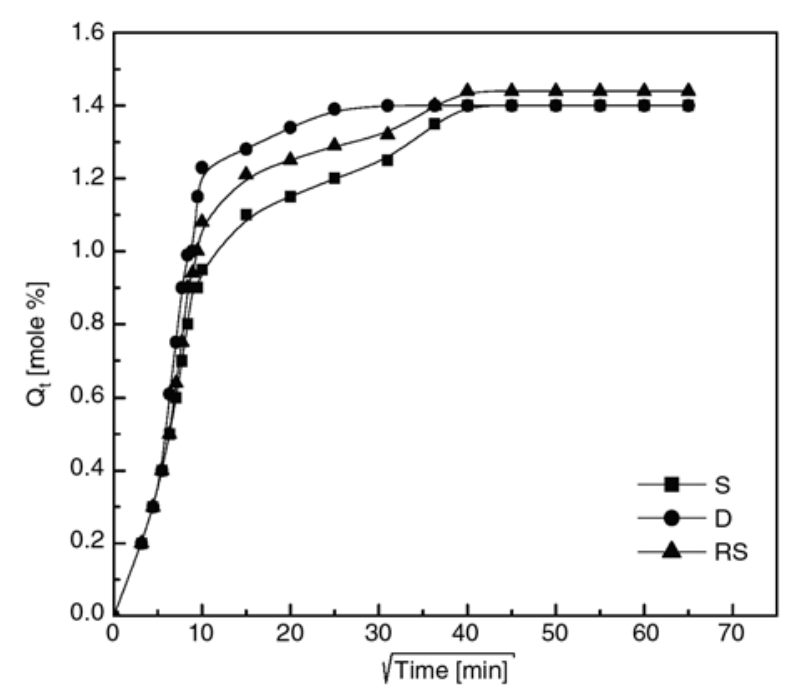

Figure 9. S-D-RS curves of S10 in benzene

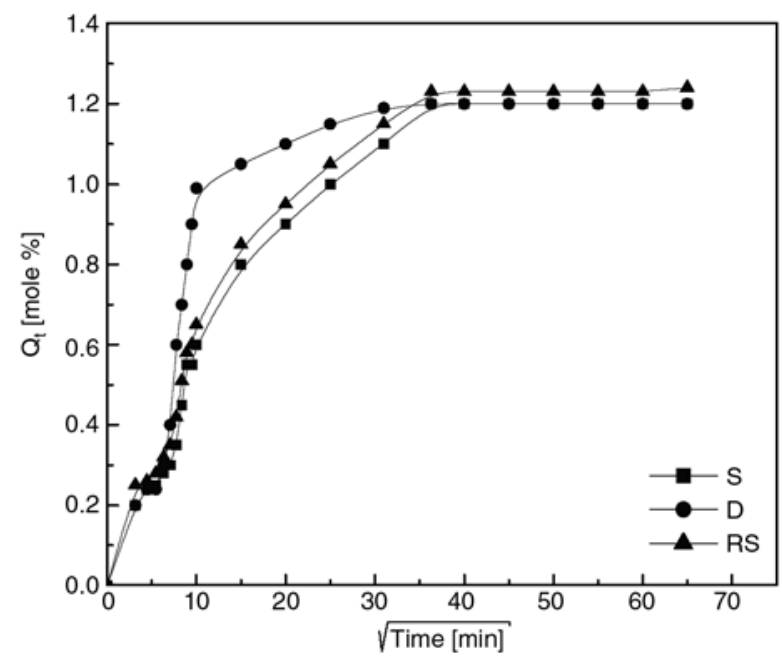

Figure 10. S-D-RS curves of H10 in toluene

benzene and H10 in toluene are given in Figures 9 and 10 respectively. The mol\% equilibrium solvent uptake for the resorption curve is found to be slightly higher than that of sorption curve. After a sorption-desorption cycle, the available free volume within the polymer matrix and the polymer segmental mobility increases and hence, the subsequent resorption process is different from that of the sorption process. Figures 9 and 10 also reveal that the rate of desorption is higher than that of sorption. In the sorption process, the solvent molecules have to penetrate into the tightly packed network and hence the rate of penetration process is low. In the desorption process, the escape of solvent molecule from the relaxed polymer chain takes place more easily.

\section{Conclusions}

The cure characteristics and solvent transport behaviour of black filled EVA have been studied. The $M_{H}$ of the composites exhibited a decreasing trend with increasing particle size and an increasing behaviour with content of filler. The solvent uptake trend of EVA has been observed to be reduced by carbon black incorporation. Among the filled samples the ISAF filled sample showed the lowest solvent uptake followed by HAF and then SRF filled samples. The mode o transport in all the cases has been observed to be anomalous. The S-D-RS experiment carried out showed that the composites accommodate more solvent after a sorption-desorption cycle.

\section{References}

[1] Landois-Garza J., Hotchkiss J. H.: Food and packaging interactions. American Chemical Society Symposium Series, Washington (1988).

[2] Seymour R. B.: Engineering polymer source book. McGraw-Hill Publishing, New York (1990).

[3] Huang R. Y. M.: Pervaporation membrane separation processes. Elsevier, New York (1991).

[4] Kulkarni P. V., Rajur S. B., Antich P., Aminabhavi T. M., Aralaguppi M. I.: Transport studies on macromolecules used as drug carriers. Journal of Macromolecular Science, Reviews in Macromolecular Chemistry and Physics, 30, 441-470 (1990).

[5] Peppas N. A.: Hydrogels in medicine and pharmacy. CRC Press, Boca Raton (1987).

[6] Guth E.: Theory of filler reinforcement. Journal of Applied Physics, 16, 20-25 (1945).

[7] Porter M.: Structural characterization of filled vulcanisates, 1. Determination of the concentration of chemical crosslinks in natural rubber vulcanisates containing high abration furnace black. Rubber Chemistry and Technology, 40, 866-882 (1967).

[8] De Candia F., Gargani L., Renzulli A.: Transport properties of filled elastomeric networks. Journal of Applied Polymer Science, 41, 955-964 (1990).

[9] Kwei T. K., Kunins C. A.: Polymer-filler interaction: Vapour sorption studies. Journal of Applied Polymer Science, 8, 1483-1490 (1964).

[10] Anfimova E. A., Lykin A. S., Anfimov B. N.: Equilibrium swelling of filled vulcanizate of natural rubber (in Russian). Polymer Science U.S.S.R., 24, 455-461 (1982).

[11] Rutherford S. W., Kurtz R. E., Smith M. G., Honnell K. G., Coons J. E.: Measurement and correlation of sorption and transport properties of ethylene-propylene-diene monomer (EPDM) elastomers. Journal of Membrane Science, 263, 57-65 (2005). 
[12] Choi S-S.: Difference in bound rubber formation of silica and carbon black with styrene butadiene rubber. Polymers for Advanced Technologies, 13, 466-474 (2002).

[13] Leblanc J. L.: Rubber-filler interactions and rheological properties in filled compounds. Progress in Polymer Science, 27, 627-687 (2002).

[14] Ismail H., Poh B. T., Tan K. S., Moorthy M.: Effect of filler loading on cure time and swelling behaviour of SMRL/ENR and SMRL/SBR blends. Polymer International, 52, 685-691 (2003).

[15] Sujith A., Unnikrishnan G., Radhakrishnan C. K., Padmini M.: Interaction of silica and carbon black fillers with natural rubber/ethylene-co-vinyl acetate matrix by swelling studies. Polymer Composites, 28, 705-712 (2007).

[16] Unnikrishnan G., Thomas S.: Molecular transport of benzene and methyl substituted benzenes into filled natural rubbers. Journal of Applied Polymer Science, 60, 963-970 (1996).

[17] Unnikrishanan G., Thomas S., Varghese S.: Sorption and diffusion of aromatic hydrocarbons through filled natural rubbers. Polymer, 37, 2687-2693 (1996).

[18] Dasan K. P., Haseena A. P., Unnikrishnan G., Alex R., Purushothaman E.: Transport characteristics of filled poly(ethylene-co-vinyl acetate) membranes. Polymers and Polymer Composites, 12, 599-617 (2004).

[19] Sujith A., Unnikrishnan G.: Barrier properties of natural rubber/ethylene vinyl acetate/carbon black composites. Journal of Materials Science, 40, 4625-4640 (2005).

[20] Leblanc J. L., Hardy P.: Evolution of bound rubber during the storage of uncured compounds. Kautschuk und Gummi, Kunststoffe, 44, 1119-1124 (1991).

[21] George S. C., Thomas S.: Carbon black filled SBR composites: The effect of rubber-filler interaction on transport. Journal of Macromolecular Science: Physics, 39, 175-195 (2000).

[22] Karasek L., Sumita M.: Characterization of dispersion state of filler and filler polymer interactions in rubbercarbon black composites. Journal of Materials Science, 31, 281-289 (1996).

[23] Wee Y-P., Wang Y-Q., Zhang H-F., Wang Y-Z., Yee D-S., Zhang A-Q., Yang J.: Rubber pristine clay nanocomposites prepared by co-coagulating rubber latex and clay aqueous suspensions. Composites Science and Technology, 65, 1195-1202 (2005).
[24] Sandrine B-C., Christian C.: Interaction of active carbon black with low- and high- molecular weight polyethylene glycol and polyethylene oxide. Journal of Applied Polymer Science, 100, 3490-3497 (2006).

[25] Moon Y. D., Lee Y. M.: Dynamics of solvent diffusion in an aromatic polyimide. Journal of Applied Polymer Science, 51, 945-954 (1994).

[26] Elwy A., Badawy M. M., Nasr G. M.: Electrical properties and penetration rate of solvent into irradiated LDPE/SBR conductive blends. Polymer Degradation and Stability, 53, 289-294 (1996).

[27] Haseena A. P., Priya Dasan K., Namitha R., Unnikrishnan G., Thomas S.: Investigation on interfacial adhesion of short sisal/coir hybrid fibre reinforced natural rubber composites by restricted equilibrium swelling technique. Composite Interfaces, 11, 489513 (2004).

[28] Billmeyer F. W.: Text book of polymer science. Wiley Interscience, Singapore (1994).

[29] Bicerano J.: Prediction of polymer properties. Marcel Dekker, New York (1993).

[30] Mark J. E., Erman B.: Rubberlike elasticity- A molecular primer. Wiley Inter Science, New York (1988).

[31] Flory P. J.: Principles of polymer chemistry. Cornell University Press, Ithaca (1953).

[32] Ellis B., Welding G. N.: Techniques in polymer science. Society of the Chemical Industry, London (1964).

[33] Crank J.: The mathematics of diffusion. Oxford University Press, Oxford (1975).

[34] Lucht L. M., Peppas N. A.: Transport of penetrants in the macromolecular structure of coals, V. Anomalous transport in pretreated coal particles. Journal of Applied Polymer Science, 33, 1557-1566 (1987).

[35] Varghese H., Bhagwan S. S., Thomas S.: Transport properties of crosslinked acrylonitrile butadiene rubber/poly(ethylene-co-vinyl acetate) blends. Journal of Polymer Science, Part B: Polymer Physics, 37, 18151831 (1999).

[36] Aminabhavi T. M., Phayde H. T. S.: Molecular transport of alkanes through thermoplastic miscible blends of ethylene-propylene random copolymer and isotactic polypropylene. Journal of Applied Polymer Science, 55, 1335-1352 (1995).

[37] Nair S. V., Sreekala M. S., Unnikrishnan G., Johnson T., Thomas S., Groeninckx G.: The role of crosslinking and crystallization on the transport characteristics of ethylene-propylene rubber membranes. Journal of Membrane Science, 177, 1-7 (2000). 